ISSN: 0514-7336

DOI: http://dx.doi.org/10.14201/zephyrus201780193199

\title{
SELLO ALIMENTARIO ROMANO RELACIONADO CON JUNO SOSPITA PROCEDENTE DEL SE HISPANO
}

\section{A Roman alimentary stamp related to Juno Sospita from South-Eastern Hispania}

\author{
Jónatan OrTiz García
}

Dpto. de Historia de la Antigüedad y de la Cultura Escrita. Facultad de Geografía e Historia-Uv. Avda. Blasco Ibánez, 28. 48010 Valencia. Correo-e: jonatan.ortiz@uv.es

Recepción: 26/09/2016; Revisión: 13/06/2017; Aceptación: 2/07/2017

Resumen: Los sellos alimentarios romanos presentan una iconografía que en ocasiones resulta de difícil interpretación. En este trabajo presentamos algunas valoraciones sobre las imágenes grabadas en ambas caras de uno de estos objetos, en concreto de un ejemplar perteneciente a una colección privada murciana. En la publicación original se defendía su relación con cultos agrarios a través de motivos que parecían remitir a la diosa Ceres. Sin embargo, hemos comprobado que la composición tiene sus paralelos más cercanos en una serie de monedas romanorrepublicanas acuñadas en el año 64 a. C. por Lucio Roscio Fabato. Esos denarios se vinculan principalmente a Juno Sospita y de manera secundaria también a los cultos egipcios de expansión mediterránea. Por ello evaluamos la posibilidad de que dicha interacción religiosa también se halle reflejada en el diseńo del sello alimentario hispano. De ser así, esta pieza ofrecería información nueva sobre los procesos de interacción cultural entre las penínsulas ibérica e itálica.

Palabras clave: ritual; culto isíaco; moneda romanorrepublicana; cabra; áspid; espigas; situla.

ABSTRACT: Roman alimentary stamps have an iconography that sometimes is difficult to interpret. In this paper, some valuations on the images displayed on both sides of one of these objects, namely an example belonging to a private collection in Murcia, are offered. In its original publication a relation to agrarian cults through motifs that would refer to the goddess Ceres was proposed. However, it is a composition having its closest parallels in a series of Roman Republican coins issued in 64 вC by Lucio Roscio Fabato. These denarii are mainly linked to Juno Sospita and secondarily also to the Egyptian cults of Mediterranean expansion. Therefore we evaluate the possibility that such religious interaction is found also reflected on the mentioned alimentary stamp is evaluated, offering new information on the processes of cultural interaction between the Iberian and the Italian Peninsulas.

Key words: ritual; Isiac cult; Roman Republican coin; goat; asp; cereal ears; situla.

\section{Introducción}

Los sellos alimentarios se documentan ampliamente en torno al mar Mediterráneo desde muy antiguo, en culturas de distinta raigambre que compartían el valor del pan y otros alimentos como objetos de uso ritual con gran carga simbólica (Galavaris, 1970: 24-39; Caseau, 2012: 120). Estos sellos, generalmente fabricados en cerámica, podían ser decorados con rica iconografía religiosa que, en ocasiones, resulta 
de difícil interpretación, y también, a veces, incluían textos más o menos elocuentes sobre su contexto de uso original ${ }^{1}$.

El empleo de la denominación "sello alimentario", en detrimento del generalmente utilizado "sello de panadero" o "bread stamp", se debe a que estas dos opciones implican la asignación del uso de estos artefactos a un grupo específico de profesionales, cuando se trata más bien de artefactos que pudieron ser utilizados en contextos diversos por personas distintas, por ejemplo, sacerdotes. Por otro lado, también pretendemos evitar la asociación de estos objetos a un producto específico, como el pan, puesto que también pudieron utilizarse para la elaboración de pasteles de distinto tipo ${ }^{2}$.

\section{Revaluación del sello murciano}

En la Península Ibérica se conocen pocos testimonios de sellos alimentarios romanos, aunque existen publicaciones de colecciones, más o menos modestas, con este tipo de piezas, así como estudios de casos concretos (Gijón y Bustamante, 2010: 16-17). Hace ya varias décadas P. A. Lillo (1981: 192) publicó un conjunto de estos artefactos de época romana procedentes del sureste hispano. Entre ellos se incluía un ejemplar de una colección privada murciana que habría sido encontrado en la villa industrial de las Canteras de Poyo Miñano, cerca de Cehegín, Murcia (Fig. 1), yacimiento para que el se propone una cronología de mediados del s. I d. C. (Lillo, 1980: 212)33.

El sello en cuestión presenta una forma redondeada y está decorado en sus dos caras (Fig. 2): por un lado, se representa un áspid erecto, un haz de tres espigas, un cadus y dos pequeños discos; y, por el otro, un hombre encapuchado junto a una cabra, una paloma y una esfera (Lillo, 1981: 191). Posteriormente, este mismo objeto se ha incluido en una publicación de Gijón y Bustamante (2010: 20 y fig. 6.3) como ejemplo hispano de "sellos de panadero" de época romana, aunque en ningún momento se ha realizado una revaluación de su iconografía.

Recurriendo a paralelos iconográficos monetales, Lillo relacionaba este sello con cultos agrarios, a partir de la presencia asociada del áspid, el haz de espigas y el supuesto cadus, que, a su juicio, estarían remitiendo a la diosa Ceres. Sin embargo, el mismo investigador reconocía que el reptil aparecía

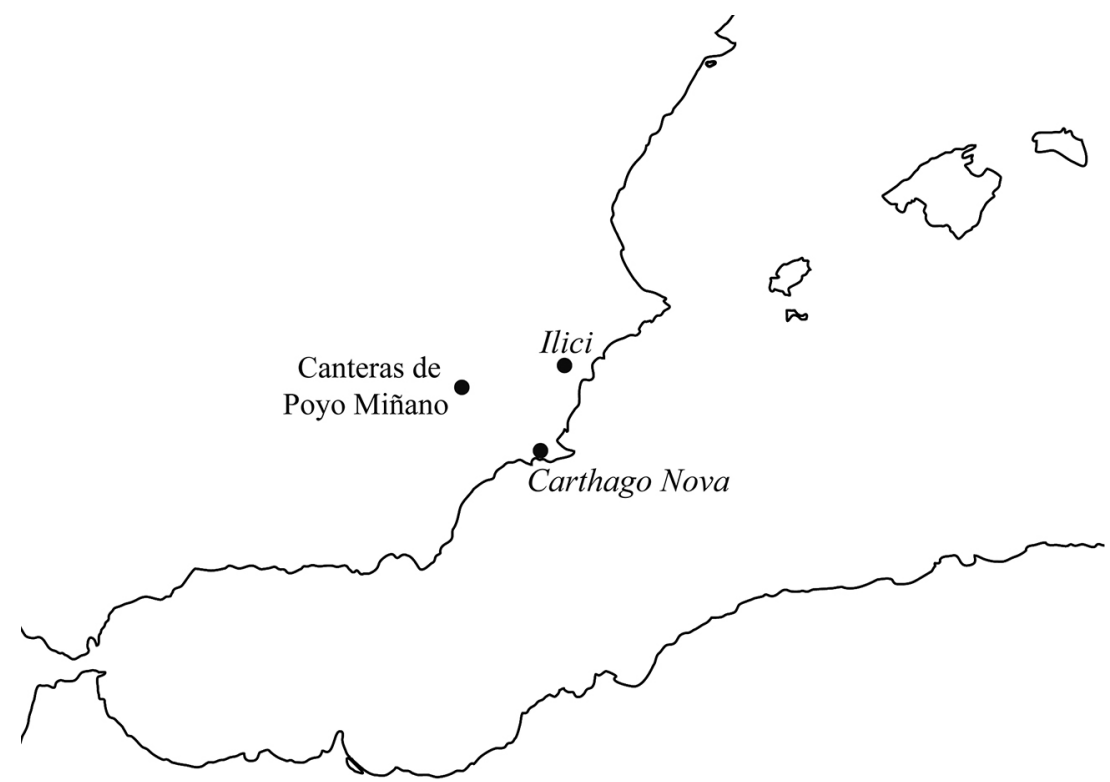

Fig. 1. Mapa con la localización de las Canteras de Poyo Miñano, Cehegín (Murcia).
1 Resultan fundamentales, al respecto de estos objetos y el marcado de alimentos, los estudios de Galavaris (1970) y Mattazzi (1999).

2 Por ejemplo, Plutarco (De Is. et Os. 30 [362F]; 50 [371D]) menciona que los egipcios estampaban imágenes de asnos e hipopótamos atados en pasteles elaborados para celebrar ciertas festividades. frecuentemente vinculado al culto a Juno Sospita en monedas republicanas acuñadas en Roma.

En la otra cara del objeto se hallaba una escena cuya interpretación resulta compleja y de la que

3 Sobre las canteras romanas de la zona de Cehegín, $c f$. Ramallo Asensio y Arana Castillo, 1987: 102-107. 
solo se pudieron identificar las mencionadas figuras del hombre y la cabra. A pesar de la ausencia de paralelos para esta segunda composición, el autor proponía que pudiera tratarse de algún tipo de relato mítico como el del sacrificio de una cabra a Apolo por parte de Numa Pompilio o que la composición estuviera haciendo referencia a algún episodio con Júpiter niño subiendo sobre dicho animal (Lillo, 1981: 191-192).

Retomando la hipótesis desechada por Lillo en relación a Juno Sospita, creemos que no solo la imagen de la serpiente podría relacionarse con el culto a esta diosa tutelar de Lanuvium ${ }^{4}$. Y es que, aparte de un famoso templo dedicado a esta divinidad en dicho lugar, nos informan las fuentes de que allí se encontraba una cueva en la que residía una serpiente, que debía ser alimentada anualmente con pasteles de cebada ofrecidos por castas muchachas. ${ }^{5}$ Si estos alimentos eran aceptados por el animal, esto supondría un año agrícola favorable y un reconocimiento de la virginidad de las jóvenes (Prop. Iv.8.314; Elian. NA XI.16). Este episodio ritual se encuentra representado en el reverso de algunas monedas republicanas acuñadas en Roma (Fig. 3), que muestran una figura femenina frente a una serpiente erguida y otro objeto detrás, que generalmente es un recipiente (Hermans, 2016: 213-215). A pesar de que Lillo relacionaba el reptil con el tipo monetal republicano, no así las espigas, el autor no fue más allá y finalmente optó por vincular el sello alimentario con Ceres.

No obstante, la asociación con Juno Sospita, que era descartada por basarse únicamente en la presencia del reptil, parece fortalecerse al observar el diseño de la otra cara del sello murciano. De nuevo recurriremos a la iconografía de las mencionadas monedas romanorrepublicanas que muestran en su anverso la cabeza de perfil de la deidad portando una piel de cabra, seguramente a partir de un préstamo iconográfico del mundo etrusco (Dumézil, 1996: 298-299; Hermans,

\footnotetext{
4 Este santuario es tratado en: Kaschnitz-Weinberg, 1955: 1-5; Coarelli, 1987: 155; Attenni, 2004; Salcedo, 2016.

5 Un trabajo reciente sobre este ritual agrícola es Hermans, 2016.
}

(C) Universidad de Salamanca
2012). En relación con esta forma de representar a la divinidad puede citarse un texto que aboga todavía más por la vinculación entre la escena del sello y el motivo de la moneda. Se trata de un episodio festivo referido a Juno que describe Ovidio $\left(A m\right.$. III.13) ${ }^{6}$ :

Cuando la flauta ha dado la señal con su solemne sonido, avanza hasta aquí la procesión anual a través de las calles engalanadas. Ante los aplausos de la multitud llevan terneras blancas como la nieve, a las que la hierba falisca alimentó en sus prados, y terneros que aún no amenazan con temible testuz, y sacado de su humilde pocilga, la víctima más pequeña, el cerdo, así como el guía de la manada con sus cuernos retorcidos sobre las duras sienes; únicamente la cabra es odiosa a la soberana deidad. Por indicación de aquella dícese que fue descubierta en la espesura de las selvas y tuvo que abandonar su huida. Todavía ahora corren los muchachos con jabalinas detrás de la delatora, que como recompensa es concedida al primero que la hiere.

Cicerón (De nat. deo. I.82) nos informa de que la cabra es un animal que la diosa aborrecía y que, por ello, mandaba cazar para luego ataviarse con su piel. Creemos que el personaje que se sitúa detrás de la cabra en el sello alimentario (Fig. 2) podría ser una de aquellas personas que seguían al animal para cazarlo en nombre de la diosa.

Continuando con el análisis de la cara donde se encuentran la serpiente y las espigas, hay ciertos aspectos que llaman la atención y que merecen un comentario más detallado. Por un lado, está el hecho de que la serpiente representada sea un áspid con la capucha de piel extendida, diferente al animal representado en las monedas romanorrepublicanas. Por el otro, consideramos que el recipiente que es identificado como un cadus romano podría ser en realidad una situla. Destacamos estas dos cuestiones ya que se trata de algo que va más allá de los simples aspectos formales pudiendo tener implicaciones de carácter religioso.

A pesar de que es posible encontrar imágenes de serpientes egipcias de frente y de perfil en objetos

6 Trad. V. Cristóbal López, ed. Gredos. 

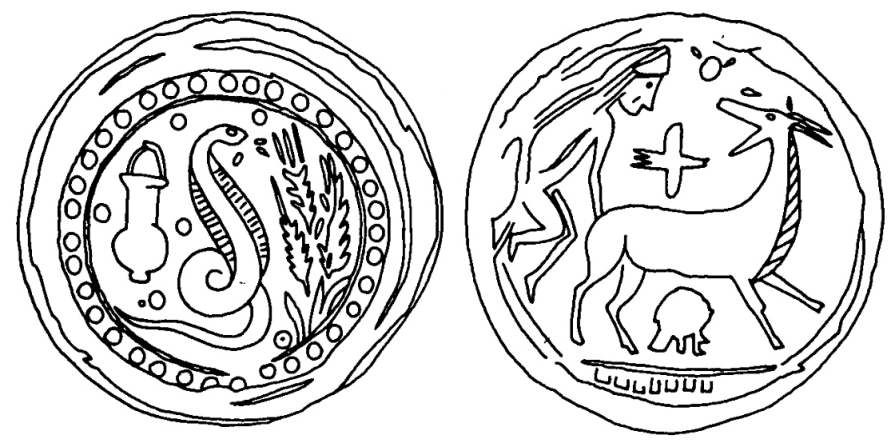

FIG. 2. Sello alimentario romano de colección privada murciana (Lillo, 1981: fig. 3).

de época romana, el tipo de imagen que aparece en el sello alimentario suele estar vinculado a contextos de cultos egipcios. Un ejemplo paradigmático de ello son algunas antefijas centroitálicas de época romana con dos de estos animales dispuestos en espejo (Amenta, 1997a,1997b; Pirelli, 1997a, 1997b). A este modo característico de mostrar los reptiles se une el hecho de que, en no pocas ocasiones, estos animales son representados en objetos isíacos con haces de espigas surgiendo de la base sobre la que se encuentran. Este es el caso, por ejemplo, de una escultura itálica de Isis lactans en cuya parte posterior del trono aparecen dos serpientes egipcias con espigas y adormidera, una portando un basileion isíaco sobre la cabeza y la otra una corona egipcia (Malaise, 1972: lám. 32).

La presencia de cultos egipcios en la zona murciana está atestiguada por inscripciones, monedas y lucernas encontradas en Cartagena y se atribuye a la influencia del rey númida Juba II (Bricault, 2008: 229; Alvar, 2012: 112-117). En cualquier caso, la

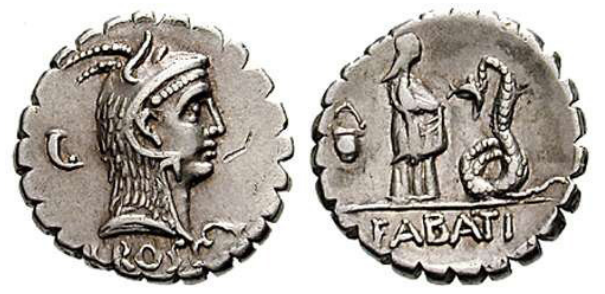

Fig. 3. Denarius serratus de Lucio Roscio Fabato; 64 a. C. (imagen reproducida con permiso de wildwinds. com y CNG sale [2002]). imagen de una serpiente, aunque sugerente, no es suficiente para proponer alguna relación entre el sello alimentario con este tipo de creencias orientales. Además, como hemos señalado previamente, el sello parece abogar por una composición muy ligada a una Juno Sospita agrícola ${ }^{7}$. No obstante, no hay que olvidar otro elemento, junto a la serpiente y las espigas, que también podría hacer pensar en algún tipo de influencia religiosa egipcia en el objeto, una posible situla.

En sus distintas formas, las situlae se encuentran entre los objetos rituales más característicos de los cultos egipcios ${ }^{8}$, con un simbolismo marcado por su asimilación al pecho de diosas celestes como Isis y a la potencia regeneradora de la leche divina (Lichtheim, 1947; Leclant, 1951) ${ }^{9}$. Se trata de un objeto religioso que, como el sistrum, viaja con Isis por el Mediterráneo y se representa siendo sujeto por la propia diosa egipcia y/o por sus fieles, sean sacerdotisas o no (Krauskopf, 2005).

Hemos identificado un ejemplo romano muy similar en la forma en que se representa este recipiente en el sello hispano en una estela funeraria romana encontrada en la necrópolis ateniense del Cerámico. En este relieve (Fig. 4) una difunta, seguidora del culto a Isis, es representada con el vestido anudado y el peinado característicos de la divinidad egipcia, y portando una situla en su mano izquierda ( $c f$. Walters, 1988: 36 y lám. 24a-b; Eingartner, 1991: 151 [n. $\left.{ }^{o} 114\right]$ y lám. Lxx.114). Creemos que este tipo de recipiente encaja mejor con el objeto grabado en el

El culto de Juno tuvo especial relevancia en Hispania, especialmente en zonas con importante presencia romana (Mangas, 1982: 332). Sobre la diosa entre la élite romana de la Bética, cf. Delgado, 1993: 341-343, 356-358. Buenos trabajos de síntesis sobre el culto a Juno y sus celebraciones asociadas son: Gagé, 1963; Dury-Moyaers y Renard, 1981. Un reciente trabajo sobre Juno Sospita y Hércules en Lanuvium es: Pasqualini, 2013.

8 Un buen muestrario de objetos rituales egipcios, incluyendo sítulas, puede encontrarse en Green, 1987.

9 A este respecto podemos recordar un pasaje de la procesión isíaca descrita en Apul. Met. XI.10, donde se describe el artefacto ritual de uno de los sacerdotes del siguiente modo: "idem gerebat et aureum vasculum in modum papillae rutundatum, de quo lacte libabat". 


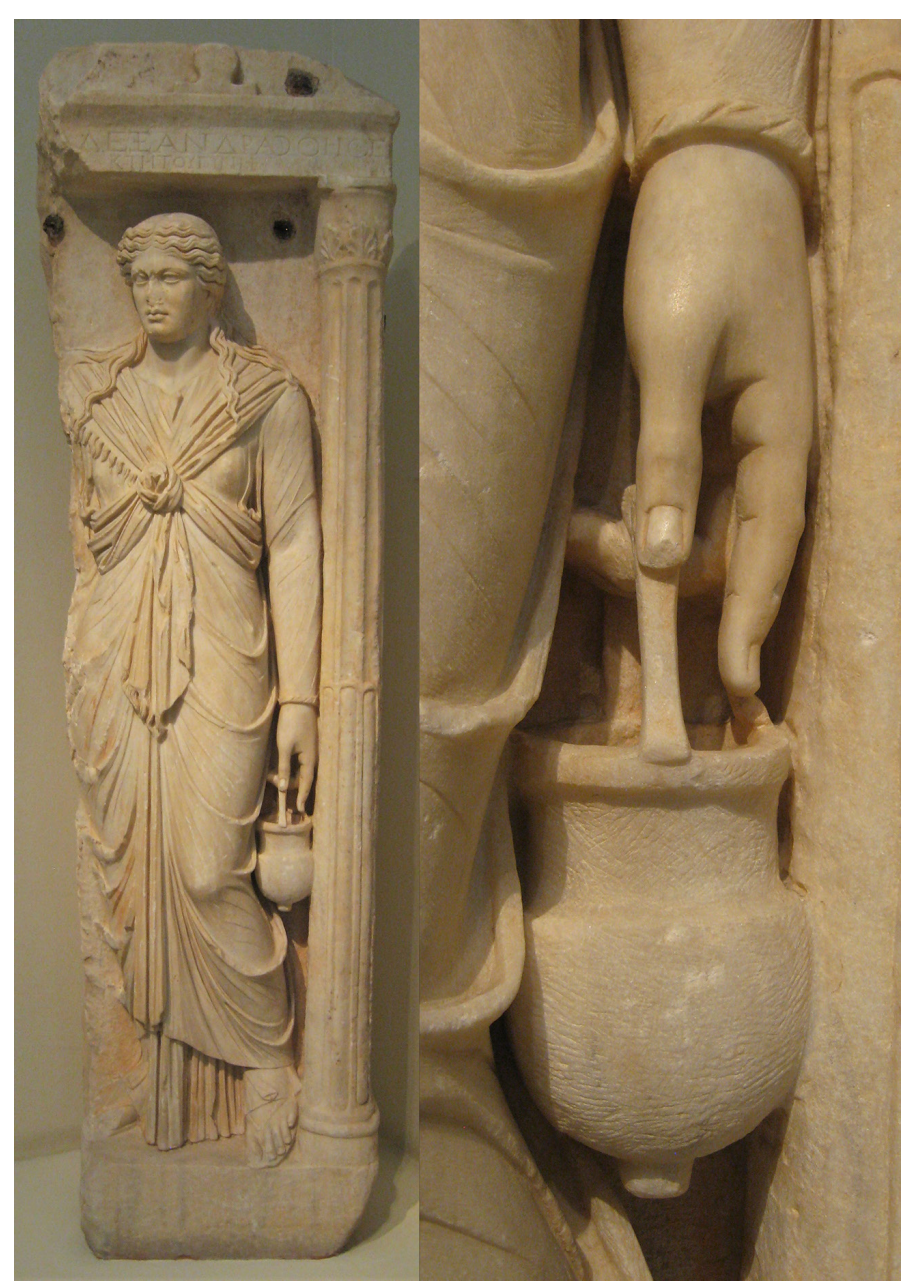

Fig. 4. Estela funeraria de una fiellsacerdotisa isíaca llamada Alexandra procedente de la necrópolis del Cerámico; datada en 130-140 d. C.; Museo Arqueológico Nacional de Atenas, n. ${ }^{\circ}$ inv. 1193.
Se ha discutido mucho sobre el porqué de estas marcas (Bricault, 2014: 186-187), pero en cualquier caso parece haber consenso en su relación al establecimiento de cultos isíacos en la ciudad de Roma en época republicana.

Además cabe señalar que algunos tipos monetarios de Lucio Papio Celso, acuñados en 79 a. C., y Lucio Roscio Fabato, en 64 a. C., incluyen motivos isíacos en el marco de una iconografía ligada a Juno Sospita. Para el primer magistrado se puede observar que en el anverso de sus denarios aparece la cabeza de la diosa con tocado animal y en el reverso hay un grifo (Crawford, 1974, t. 1: 398-399; $R R C$ 384/1); mientras que para el segundo, cuyo diseño de anverso es el mismo, aparece en reverso el ritual lanuviano de la serpiente (Crawford, 1974, t. 1: 439-440; RRC 412/1). No sabemos hasta qué punto es significativo que precisamente en las últimas monedas republicanas con motivos isíacos, las de Lucio Roscio Fabato, sea donde encontremos la conjunción de la imagen de Juno Sospita, el ritual lanuviano de la serpiente y los motivos isíacos. Pensamos que quizás podría tratarse del culmen de una tradición monetal y religiosa que arrancó años atrás, pero que no encontró una continuidad.

\section{Consideraciones finales}

sello alimentario hispano, más que su identificación como cadus, una especie de orza destinada al almacenaje y transporte de productos líquidos y áridos en un formato menor a un ánfora, aunque parecido en forma a esta ( $c f$. por ejemplo: Hdt. III.20.1; Verg. I.195; Mart. I.43.9, I.55.10; Plin. $N H$ XV.33, Xv.82, xvIII.307-308).

$\mathrm{Al}$ respecto de esta posible relación entre Juno Sospita e Isis debemos volver a las monedas republicanas. Algunas de las acuñadas en la primera mitad del s. I a. C. tienen, tanto en anverso como en reverso, motivos isíacos: un basileion, un sistrum o una situla (Bricault, 2014: lám. 10, Roma 9a-f.).
Finalmente, queremos mencionar que, aunque es difícil precisar el uso específico del sello alimentario de Murcia, sobre todo porque desconocemos su contexto de hallazgo y uso, es interesante que la iconografía remita precisamente a un ritual anual que incluía la ofrenda de un pastel de cebada a Juno Sospita por parte de jóvenes vírgenes en Lanuvium. Más allá del trasfondo agrario del objeto, habría que plantear la posibilidad de que el pan o el pastel que fuera marcado con este sello pudieran tener relación con una práctica ritual similar, o al menos que la rememorara en el lugar donde se empleara el artefacto. Dicha ceremonia podría haber tenido lugar 
en la región murciana, aunque, dado que se trata de un hallazgo descontextualizado, es obligado mantener cierta cautela al respecto, ya que pudo tratarse incluso de un producto importado. Por otro lado, la posible interacción con los cultos egipcios puede plantearse como hipótesis ante la ya constatada presencia de dicha relación en monedas republicanas de ceca romana, que fueron acuñadas por personajes oriundos de Lanuvium, donde el culto a Juno Sospita tenía como ritual más reconocido precisamente aquel de la alimentación de la serpiente. En cualquier caso, el contacto e intercambio entre los cultos de Juno Sospita e Isis, si se produjo ya en territorio itálico, pudo haber llegado a la zona murciana desde allí entre finales del s. I a. C. y el s. I d. C., fecha posible esta última para el sello alimentario en cuestión. De este modo, se constataría una nueva vía de penetración de los cultos orientales en la región del sureste hispano distinta a la vía africana de Juba II. Nuevos testimonios resultarán fundamentales para entender mejor el valor del sello alimentario murciano como documento religioso.

\section{Bibliografía}

Alvar, J. (2012): Los cultos egipcios en Hispania. Besançon: Presses universitaires de Franche-Comté.

Amenta, A. (1997a): "iv.234 Antefissa marmorea con urei”. En Arslan, E. A. (ed.): Iside. Il mito, il misterio, la magia. Milano: Electa, p. 236.

Amenta, A. (1997b): "Iv.235 Antefissa marmorea con urei”. En Arslan, E. A. (ed.): Iside. Il mito, il misterio, la magia. Milano: Electa, p. 236.

Attenni, L. (2004): "Lanuvio. Il santuario di Giunone Sospita. Osservazioni sulla fase arcaica e tardoreplubblicana”. En GHini, G. (ed.): Lazio e Sabina 2. Secondo incontro di studi sul Lazio e la Sabina (Roma, 2003). Roma: De Luca, pp. 221-226.

Bricault, L. (2008): "Afrique du Nord". En Bricault, L. (dir.): Sylloge nummorum religionis isiacae et sarapiacae (SNRIS). Paris: De Boccard, pp. 225-232.

Bricault, L. (2014): "Sylloge Nummorum Religionis Isiacae et Sarapiacae. Supplément I”. En BRICault, L. y Veymiers, R. (dirs.): Bibliotheca Isiaca III. Bordeaux: Ausonius Éditions, pp. 245-284.
Caseau, B. (2012): "Magical Protection and Stamps in Byzantium”. En Regulski, I.; Duistermaat, K. y Verkinderen, P. (eds.): Seals and Sealing Practices in the Near East. Developments in Administration and Magic from Prehistory to the Islamic Period. Proceedings of an International Workshop at the Netherlands-Flemish Institute in Cairo on December 2-3, 2009. Lovaine-Paris-Walpole: Peeters, pp. 115-132.

Coarelli, F. (1987): I Santuari del Lazio in età repubblicana. Roma: La Nuova Italia scientifica.

Crawford, M. H. (1974): Roman Republican coinage. London: CuP.

Delgado, J. A. (1993): "El culto a Júpiter, Juno y Minerva entre las élites béticas durante el alto Imperio Romano", Gerión, 11, 1993, pp. 337-363.

DumÉzIL, G. (1996): Archaic Roman religion; with an appendix on the religion of the Etruscans. BaltimoreLondres: Johns Hopkins University Press.

Dury-Moyaers, G. y Renard, M. (1981): "Aperçu critique de travaux relatifs au culte de Junon". En Aufstieg und Niedergang der römischen Welt, II.17.1. Berlín: Walter de Gruyter, pp. 142-202.

EINGARTNER, J. (1991): Isis und ihre Dienerinnen in der Kunst der römischen Kaiserzeit. Leiden-New York-Copenhaguen-Köln: Brill.

GaGÉ, J. (1963): Matronalia. Essai sur les dévotions et les organisations cultuelles des femmes dans l'ancienne Rome. Bruxelles: Latomus.

Galavaris, G. (1970): Bread and the Liturgy: The Symbolism of Early Christian Bread Stamps. Madison-Milwaukee-London: Univ. of Wisconsin Press.

Gijón, M. E. y Bustamante, M. (2010): "Los sellos romanos de panadero: una aproximación a su estudio a partir de los depositados en el Museo Nacional de Arte Romano (Mérida)", Huelva en su Historia, 13, 2010, pp. 15-30.

Green, C. I. (1987): The Temple Furniture from the Sacred Animal Necropolis at North Saqqâra, 1964-1976. London: Egypt Exploration Society.

Hermans, R. (2012): "Juno Sospita: A Foreign Goddess through Roman Eyes". En RoselaAr, S. (ed.): Processes of Integration and Identity Formation in the Roman Republic. Leiden: Brill, pp. 327-336.

Hermans, R. (2016): "Juno Sospita and the draco: Myth, Image, and Ritual in the Landscape of the Alban Hills". En McInerney, J. y I. Sluiter. I (eds.): Valuing Landscape in Classical Antiquity. Natural Environment and Cultural Imagination. Leiden: Brill, pp. 196-227. 
Kaschnitz-Weinberg, G. (1955): "Das Kultbild der Juno Sospita in Lanuvium”. En BRuns, G. (ed.): Festschrift für Carl Weickert. Berlin: Gebr. Mann, pp. 1-5.

Krauskopf, I. (2005): "Situla". En Thesaurus cultus et rituum antiquorum (ThesCRA). v. Personnel of cult. Cult instruments. Los Angeles: The J. Paul Getty Museum, pp. 244-249.

Leclant, J. (1951): "Le rôle du lait et de l'allaitement d'après les Textes des Pyramides", Journal of Near Eastern Studies, 10 (2), 1951, pp. 123-127.

Lichtheim, M. (1947): "Situla n. 11395 and some remarks on Egyptian Situlae", Journal of Near Eastern Studies, 6 (3), pp. 169-179.

Lillo, P. A. (1980): "Algunos materiales procedentes de las canteras de Poyo Miñano (Cehegín)", Anales de la Universidad de Murcia, xxxviII (4), 1980, pp. 209-217.

Lillo, P. A. (1981): "Contribución al estudio de 'los sellos de panadero' del Sureste", Memorias de Historia Antigua, 5, 1981, pp. 187-194.

Malaise, M. (1972): Inventaire préliminaire des documents égyptiens découverts en Italie. Leiden: Brill.

Mangas, J. (1982): “Religión romana de Hispania”. En Menéndez Pidal, R. y Jover, J. M. (eds.): Historia de España. España Romana (218 a. J. c.-414 de J. c.). Vol. 2. La sociedad, el derecho, la cultura. Madrid: Espasa Calpe, pp. 323-369.

Matazzi, P. (1999): Le matrici fittili decorate di cultura punica in Sardegna. Roma: Univ. degli Studi La Sapienza.

Pasqualini, A. (2013): "Giunone Sospita ed Ercole a Lanuvio". En Pasqualini, A. (ed.): Latium vetus et adiectum. Ricerche di Storia Religione e Antiquaria. Tivoli: Tored, pp. 495-521.

Pirelli, R. (1997a): "Iv.232 Antefissa con serpenti”. En Arslan, E. A. (ed.): Iside. Il mito, il misterio, la magia. Milán: Electa, p. 235.

Pirelli, R. (1997b): "Iv.233 Antefissa con serpenti”. En Arslan, E. A. (ed.): Iside. Il mito, il misterio, la magia. Milán: Electa, p. 235.

$R R C=$ CRAWFord, M. H. (1974).

Ramallo, S. F. y Arana, R. (1987): Canteras romanas de Carthago nova $y$ alrededores (Hispania Citerior). Murcia: Univ. de Murcia.

SAlCEdo, F. (2016): Tusculana marmora: escultura clásica en el antiguo Tusculano. Madrid: CSIc.

Walters, E. J. (1988): Attic Grave Reliefs That Represent Women in the Dress of Isis. Princeton: ASCSA. 